\title{
Physiological Redundancy and the Integrative Responses to Exercise
}

\author{
Michael J. Joyner ${ }^{1}$ and Jerome A. Dempsey ${ }^{2}$ \\ ${ }^{1}$ Department of Anesthesiology and Perioperative Medicine, Mayo Clinic, Rochester, Minnesota 55905 \\ ${ }^{2}$ John Rankin Laboratory of Pulmonary Medicine, University of Wisconsin-Madison, Madison, \\ Wisconsin 53706 \\ Correspondence: joyner.michael@mayo.edu
}

\begin{abstract}
The biological responses to acute and chronic exercise are marked by a high level of physiological redundancy that operates at various levels of integration, including the molecular, cellular, organ-system, and whole-body scale. During acute exercise, this redundancy protects whole-body homeostasis in the face of 10 -fold or more increases in whole-body metabolic rate. In some cases, there are "trade-offs" between optimizing the performance of a given organ or system versus whole-body performance. Physiological redundancy also plays a key role in the adaptive responses to exercise training and high levels of habitual physical activity, including the positive effects of regular exercise on health. Appreciation of the general principles of physiological redundancy is critical to (1) gain an overall understanding of short- and long-term responses to exercise, and (2) place physiological responses occurring at various levels of integration in perspective.
\end{abstract}

$\mathrm{T}_{\mathrm{t}}^{\mathrm{h}}$ he purpose of this essay is to provide historical and intellectual context relevant to the modern study of the physiological and biological responses to muscular exercise and physical activity. Because so much current exercise-related research is focused at the cellular and molecular level, we would like to highlight four key principles related to the study of exercise. Although these principles have been known for many years, it is our perspective that in an era of science dominated by powerful reductionist tools, they are easy to underappreciate. This underappreciation can then lead to a lack of physiological perspective and a tendency to overinterpret specific cellular or molecular mechanisms as obligatory or dominant components of complex multiscale phenomenon. In this context, our target audience is very broad-ranging, from clinicians interested in the health effects of exercise to basic scientists focused on molecular responses to exercise. To frame our discussion, we focus on four key principles:

First, at almost every level of integration, the physiological responses to exercise or the effects of exercise can be dramatic. This is true at the level of cells, organs, systems, and whole organisms even when considering things like population health, individual health span, and also longevity. This is also true for the acute responses to a bout of exercise and the longerterm adaptations and physiological and ana-

Editors: Juleen R. Zierath, Michael J. Joyner, and John A. Hawley

Additional Perspectives on The Biology of Exercise available at www.perspectivesinmedicine.org

Copyright (C) 2018 Cold Spring Harbor Laboratory Press; all rights reserved; doi: 10.1101/cshperspect.a029660

Cite this article as Cold Spring Harb Perspect Med 2018;8:a029660 
tomical remodeling that occurs in response to exercise training.

Second, key responses to exercise are redundant, meaning that multiple biological mechanisms or pathways contribute to them. This also means that when an individual pathway is blocked or attenuated via an experimental intervention or perhaps pathophysiological condition, major effects on higher-order responses or outcomes may be absent or less than expected.

Third, skeletal muscle contractions are associated with systemic responses and there are remote effects on tissues other than the contracting muscles. Some of these systemic responses occur rapidly and are a result of neurally mediated feedforward and feedback mechanisms. Others are the result of the mechanical effects of exercise on tissues like blood vessels and bone, factors released by endocrine organs, and substances released from the contracting muscles themselves.

Fourth, a substantial portion of the risk reduction and improved health associated with exercise and physical activity cannot be explained by changes in traditional and commonly measured risk factors, like blood lipids, glucose tolerance, and blood pressure.

In addition to focusing on these four topics, we will briefly discuss "what is exercise," and how exercise is related to the frequently used companion term "physical activity." We will also point out that "work physiology" set the stage for modern studies of exercise. For each of our major areas of emphasis, we will provide what we believe are outstanding examples that highlight the key principles we are discussing. These examples will range from observations made at the cellular to those made at the population level.

\section{MAGNITUDE OF THE PHYSIOLOGICAL CHALLENGES WITH EXERCISE}

The physiological challenges associated with exercise can be enormous. To help frame the discussion that follows, some of the acute responses to endurance exercise are highlighted. At rest, oxygen consumption in lean young healthy humans is $\sim 3.5 \mathrm{ml} \cdot \mathrm{kg}^{-1} \cdot \mathrm{min}^{-1}$. In untrained humans, it can increase 10- to 15-fold with exercise at maximum (e.g., an all-out $3000 \mathrm{~m}$ run) and in highly trained endurance athletes, oxygen consumption can increase 20to 25-fold. These are approximate values seen in lean young men, and average values are $10 \%$ to $15 \%$ lower in women when expressed per $\mathrm{kg}$ due primarily to differences in body composition. As humans age, there is an unavoidable decline in maximum oxygen uptake of $\sim 10 \%$ per decade starting in the fourth decade of life. But the rate of this decline is modified by many factors, including the individual's lifelong exercise habits (Trappe et al. 2013)

When considered on a whole-body basis, maximal oxygen consumption in the range of 3 to 6 or more $\mathrm{L} \cdot \mathrm{min}^{-1}$ is possible, again with somewhat lower average values seen in women because of the differences in body size and body composition. Additionally, similar increases in $\mathrm{CO}_{2}$ production are seen. As impressive as the magnitudes of these changes are, they are even more impressive when considering that most or all of this additional metabolic activity is in the contracting skeletal muscles. Without going into detail, in a $70 \mathrm{~kg}$ male, perhaps 10 to $15 \mathrm{~kg}$ of muscle is being used to perform the type of exercise outlined above (for more discussion, see Joyner and Casey 2015). This means that, at least in some humans during heavy exercise, $\mathrm{O}_{2}$ consumption in the active skeletal muscles is on the order of $500 \mathrm{ml} \cdot \mathrm{kg}^{-1} \cdot \mathrm{min}^{-1}$ with similar levels of $\mathrm{CO}_{2}$ production occurring. These values are at least several hundred-fold above the very low values observed in resting muscle. Finally, depending on the training status of the individual, it is possible for humans to perform sustained exercise at $60 \%$ to $90 \%$ of maximum oxygen consumption for an hour or more.

At the same time, these impressive changes in metabolic activity are occurring within the skeletal muscle; there are only modest or minimal changes in key physiological variables like body temperature, arterial blood gases, blood glucose, and blood pressure. Figure 1 highlights some of these multiscale phenomena. 
Physiological Redundancy and Exercise

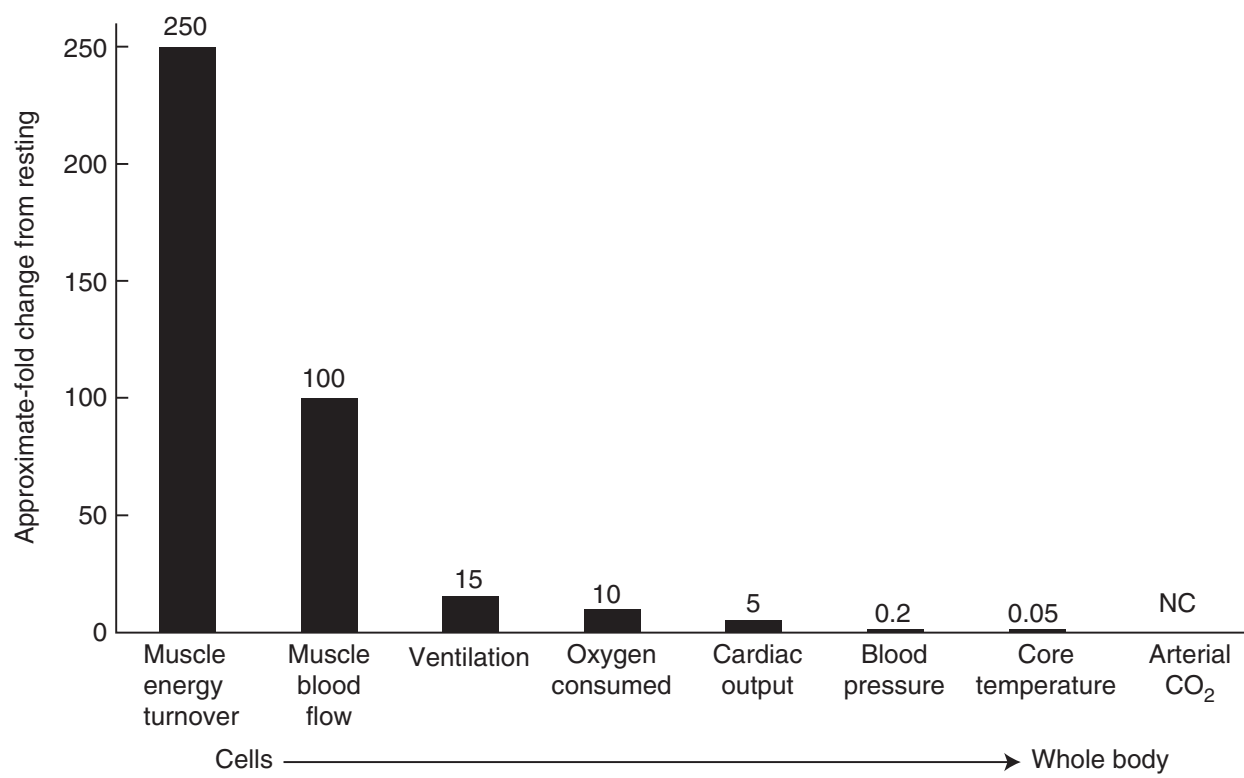

Figure 1. During sustained heavy aerobic exercise in a fit but not athletically gifted human, whole-body oxygen consumption can increase $\sim 10$-fold. Energy turnover in the contracting muscles can increase up to $\sim 250$-fold, evoking a roughly 50 - to 100 -fold increase in skeletal muscle blood. This increase in flow is likely due in part to substances released by the contracting muscles. Relatively smaller increases in blood flow are required to meet the demands of the muscle for oxygen because of the nature of $\mathrm{O}_{2}$ binding and release from hemoglobin. The increase in minute ventilation is governed by a myriad of neural feedforward and feedback mechanisms. Cardiac output increases as a result of neurally mediated increases in heart rate and an increase in stroke volume caused in part by the mechanical properties of the heart and how they respond to increases in filling pressure. So-called "regulated" physiological variables like blood pressure, core temperature, and arterial $\mathrm{CO}_{2}$ show minimal changes. These responses highlight the robust (and redundant) nature of the local to whole-body physiological responses and control systems that minimize threats to homeostasis during exercise.

\section{EXERCISE VERSUS PHYSICAL ACTIVITY}

For the purposes of this essay, exercise is physical activity that is planned, structured, repetitive, and purposeful. Physical activity is any body movement that uses muscles and requires energy. Exercise is also a word with many possible uses and connotations. In the biomedical context, it frequently has something to do with "muscular exercise" and, as implied above, it includes humans performing structured physical activity with the goal of improving their health or physiological capacity for work. The term "muscular exercise" appeared in the indexed biomedical literature in the later 1800 s and its use peaked from $\sim 1950$ to $\sim 1980$. It has generally been replaced by the more generic "exercise" over time.
One of the more interesting early references with muscular exercise in the title was written by 94-year-old Sir Hermann Weber, M.D. F.R.C.P-a dedicated mountain climber-and published in 1918. The paper was titled "On the Influence of Muscular Exercise on Longevity" (Weber 1918; Jacobi 1919). In this paper, Weber identified 10 key positive physiological actions of muscular exercise, which anticipate much of what is being discussed and studied today. His list included:

1. Increased afflux of blood to the muscles with each contraction.

2. Increased nutrition of the muscle combined with improved metabolism and production of body heat. 
M.J. Joyner and J.A. Dempsey

3. Increase of exchange of fluid between blood and tissues.

4. Facilitation of the removal of waste products.

5. Preservation of the elasticity of the thorax and lungs.

6. Abundant supply of oxygen for the blood and the metabolism.

7. Maintenance of the healthy condition of the organs of circulation, from the heart to the smallest arteries, capillaries, and lymphatics.

8. Massage of the bones, keeping up the healthy condition of the bone substance and the bone marrow, and through this the formation of a sufficiency of blood efficient for the fight with hostile bacteria entering the blood.

9. Increase of the resisting power of the body against disease.

10. Persistence of the working capacity of the brain centers, which initiate the action of the different sets of muscles.

In 1960, the search term "physical activity" yielded nine citations in PubMed, including a paper that remains highly topical on physical activity and obesity from the New England Journal of Medicine (Chirico and Stunkard 1960). In 2015, more than 8000 indexed papers were linked to the search term physical activity.

In a broad sense, (muscular) exercise might be thought of as consisting of a single bout or, more generally, a program of structured physical activity with a specific goal in mind. Usually, the focus of exercise training programs is getting in "better shape," motivated by a desire for better health, which typically means improving cardiorespiratory fitness. It can also mean getting stronger or acquiring or improving a skill used in recreational or competitive athletic competitions or games of various sorts. Physical activity is a more generic term and can include exercise, training for sport, play, occupational activity, and things like active transportation. Thus, exercise is a subset of physical activity differenti- ated in large part by intentionality or purpose. Additionally, a recreational jogger who is trying to stay in shape almost certainly has very different goals than an elite endurance athlete trying to reach the limit of his or her biological adaptability and excel in high-level competition.

For scientific purposes, physical activity is usually assessed as part of population studies investigating the causes of disease. It is also used to categorize human research participants before studying an outcome variable thought to be modified by physical activity. For example, groups of high and low physical activity subjects might be recruited to study on a cross-sectional basis the effects of physical activity on some element of metabolic regulation. Routine physical activity can also be experimentally altered to study its effects on health-related outcomes. Recent notable examples include efforts to reduce the steps per day taken by normally active subjects to study the impact of reduced activity on body composition and metabolic regulation (Olsen et al. 2008). Even more dramatic (and reversible) deconditioning responses are seen with brief ( 3 weeks) periods of bed rest, showing the impressive plasticity of key physiological adaptations to changes in physical activity. In fact, the effects of 3 weeks of bed rest on cardiorespiratory fitness have been likened to 30 years of aging (McGuire et al. 2001).

This current interest in physical activity and population health is interesting to consider in the context of work physiology. Many of the early studies of exercise-related topics were focused on individuals (almost exclusively men) performing manual labor in industrial settings. In fact, the mission of many early exercise research units like the Harvard Fatigue Laboratory (which was housed in the Business School) was to improve the productivity of individuals performing manual labor. This trend was also part of the larger hygiene movement of the late 19 th and early 20th centuries. It offers a sharp contrast to the current low-activity, high-calorie environment seen in the developed world (Tipton 1998; Church et al. 2011; Scheffler 2015).

There are parallels in animal experiments, especially studies of rodent models. In some studies, the animals are not provided access to 
Physiological Redundancy and Exercise

exercise wheels. In others, they are permitted to use the wheels on a "voluntary" basis and, in some studies, the animals undergo formal training programs that attempt to mimic the programs used in human studies and by athletes (Holloszy 1967; Morris et al. 2008; Safdar et al. 2011). Of note, cage confinement of experimental animals and the current sedentary state of most humans (although clearly not normal in an evolutionary context) is paradoxically called the control state in most studies. In contrast, the exercise or physical activity is typically characterized as the intervention.

\section{MAJOR COMPONENTS OF EXERCISE}

The most fundamental component of exercise is the contraction of one or more skeletal muscles. However, it should be noted that while electrical stimulation of an isolated muscle can generate a contraction and evoke a number of local responses, many other elements of exercise are missing in this paradigm (Joyner and Casey 2015). For example, the neural signals or "central command" that emanate from the brain to cause muscle contractions in conscious animals during exercise are absent in studies of electrically stimulated muscle. These signals provide important feedforward signals that govern, in part, the systemic cardiovascular, respiratory, and endocrine responses to whole-body exercise (Mitchell 2013). The latter responses might be described as "service" functions designed to preserve whole-body homeostasis in the face of the demands by contracting muscles for oxygen and fuel along with the need for waste and heat removal necessitated by vast increases in their metabolic rate. For example, during wholebody voluntary exercise like running or cycling, if minute ventilation did not increase dramatically to eliminate the increased $\mathrm{CO}_{2}$ production from the contracting muscles, whole-body $\mathrm{pH}$ could decrease to lethal levels in a matter of minutes or less. Accordingly, not only does the ventilatory response to exercise occur precisely in proportion to increased muscle $\mathrm{CO}_{2}$ production-thereby protecting acid base status-but the response is extremely efficient in terms of minimizing the increased work of breathing at- tending the more than 20 -fold increase in ventilation. Incredibly, with aging, as lung function deteriorates and dead space increases, minute ventilation at a given level of exercise increases. Thus, despite the increased dead space with aging, alveolar ventilation stays exactly the same at a given level of $\mathrm{CO}_{2}$ production. This means that arterial $\mathrm{CO}_{2}$ is maintained during exercise at age 75 just as at it at age 30 , and in both cases the values are essentially identical to resting until very heavy levels of exercise (Johnson et al. 1994). This is an example of a physiological trade-off whereby more work of breathing is tolerated so that arterial blood gases and acid-base status can be maintained within a narrow range.

The physiological responses to exercise can be considered on the basis of an acute bout or in response to repeated bouts over months or years known as training. The goals of exercise training can vary from things as disparate as enhancing motor recovery after a stroke, preventing chronic diseases, and preparation for elite athletic competition. In an experimental context, there are both human and animal models that can be used to address specific questions about the acute and chronic biological responses to exercise. Importantly, many outcomes associated with exercise studies are context-specific and dependent on the specifics of the stimulus (Asmussen 1981). For example, in studies of acute exercise, the mass of the active muscles, the duration of the contractions, the extent of the muscle shortening, and the duration of the exercise bout can all influence key responses. For training studies, the frequency, intensity, duration, and specificity of training programs can vary in innumerable combinations. Because there are so many possible variations of exercise and exercise training, it can be difficult to develop generalized guidelines based on data from a given intervention (Fig. 2).

\section{THE EFFECTS OF EXERCISE AND PHYSICAL ACTIVITY CAN BE DRAMATIC}

To continue with the point made in Figure 2, in this section we highlight observations from several experimental models showing the magnitude of the responses that can be seen during 
M.J. Joyner and J.A. Dempsey

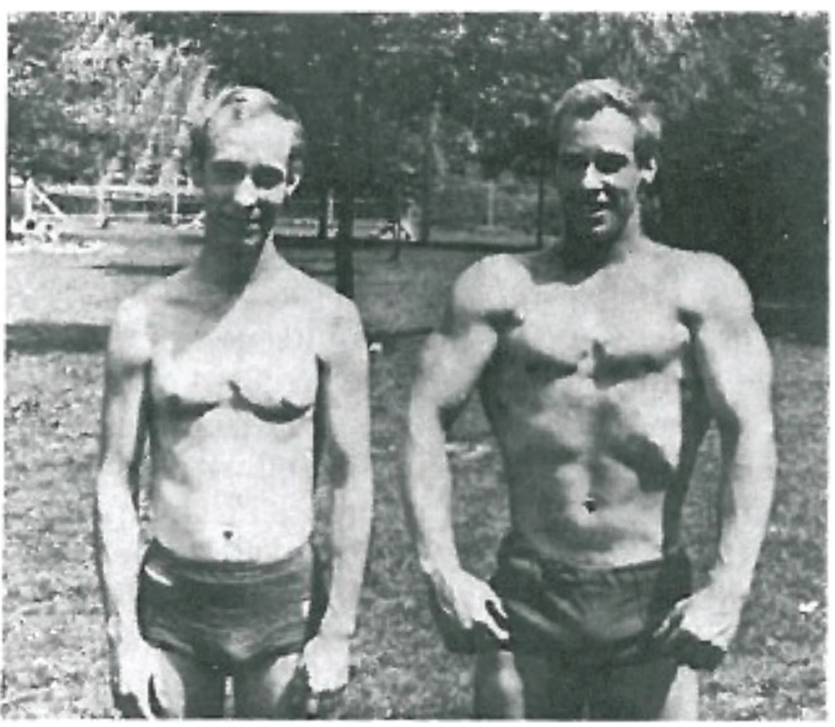

Figure 2. Phenotypic differences in identical twins who performed different forms of exercise training over many years. The twin on the left was engaged in distance running while his brother on the right was a strength-training enthusiast. (From Keul et al. 1981; reprinted, with permission, from Wolters Kluwer/American Heart Association (C) 1981.)

exercise or that are associated with differing levels of physical activity. In response to a single bout of contractions, glucose uptake in isolated skeletal muscle can increase $\sim 20$-fold (Holloszy and Narahara 1965; Holloszy 1967). As noted above, blood flow to contracting muscle can increase 100 -fold above baseline resting values (Laughlin and Armstrong 1982; Andersen and Saltin 1985; Musch et al. 1987). In untrained healthy young males, cardiac output can increase fourfold to values of $\sim 20 \mathrm{~L} / \mathrm{min}$, and minute ventilation can increase $>10$-fold and exceed $100 \mathrm{~L} / \mathrm{min}$ (Joyner and Casey 2015). Of note, a regulation soccer (foot) ball has a volume of $\sim 5.5 \mathrm{~L}$.

With endurance exercise training, the mitochondrial content of skeletal muscle subjected to training can essentially double over a period of months (Holloszy 1967). Likewise, maximal oxygen uptake can increase $40 \%$ in some untrained subjects in response to vigorous training programs as short as 10 weeks in duration. Additionally, these impressive increases in maximal oxygen uptake are accompanied by parallel increases in cardiac output and minute ventilation (Hickson et al. 1977; Bacon et al. 2013;
Howden et al. 2015). Highly trained elite endurance athletes can have hearts that are 50\% to $100 \%$ larger in size than healthy subjects, and values for minute ventilation of $\sim 150$ to $200 \mathrm{~L} /$ min have been seen (Ekblom and Hermansen 1968).

In fact, some elite human athletes and especially thoroughbred racehorses have such excessive ventilatory requirements during heavy exercise that they encroach on the mechanical limits of the lung and respiratory muscles (Dempsey et al. 1984; Bayly et al. 1989; Johnson et al. 1992). The excessive intrathoracic pressures these athletes generate also constrain the stroke volume output from the left ventricle, and blood flow through the lung is accompanied by high pulmonary vascular pressures that provide substantial afterload on the right side of the heart. Finally, at very high cardiac outputs, the transit time of red cells through the lungs might be inadequate to fully oxygenate the venous blood.

From a population perspective, even modest levels of exercise training and fitness or high levels of occupational or recreational physical activity are associated with $30 \%$ to $50 \%$ reduc- 
Physiological Redundancy and Exercise

tion in all cause and cardiovascular mortality (Morris et al. 1953; Moore 2012; Feldman et al. 2015; Lavie et al. 2015). Importantly, although the relationship between fitness and/or physical activity is curvilinear, a very high level of either appear to be highly protective. There are also remarkable examples of maintained physical fitness in octogenarians who have participated in lifelong physical activity (Trappe et al. 2013). These observations suggest that lifelong health benefits and disease protection can be obtained by continued engagement in vigorous exercise training and physical activity.

There has also been interest in elucidating the molecular mechanisms that might explain differing interindividual $\mathrm{VO}_{2 \max }$ (e.g., cardiorespiratory fitness) responses to standard training programs lasting from 10 to 20 weeks (for discussion of the molecular transducers, see Hawley et al. 2014). This interest is fueled by the concept that there can be responders and "nonresponders" to training (Sarzynski et al. 2016). However, the concept of responders and nonresponders has been challenged by a number of investigators who argue that with an adequate stimulus a training response can be seen in essentially all healthy humans (Bacon et al. 2013; Howden et al. 2015), and "nonresponder" is more likely equivalent to "noncompliant." Of note is a recent study that carefully varied the dose of training in healthy young men (Montero and Lundby 2017). All of the participants engaging in high-dose training responded. In the individuals who engaged in low- or medium-dose training, some nonresponders were seen. However, when the dose of training was increased in these men, they all became responders. Additionally, the molecular signatures that are thought to be associated with the magnitude of the $\mathrm{VO}_{2 \max }$ response to training have no clear link to the key physiological determinants of oxygen transport that explain $\mathrm{VO}_{2 \max }$ (Lundby et al. 2016). Finally, after extensive searching, a clear genetic explanation for the very high $\mathrm{VO}_{2 \max }$ values seen in elite endurance athletes has not been identified (Rankinen et al. 2016).

Together, these disparate observations ranging from isolated skeletal muscle to human populations emphasize the dramatic effects of acute and chronic exercise and high levels of habitual physical activity. They also highlight that much remains to be learned about how events at the cellular and molecular level might ultimately explain key elements in the wholebody responses to exercise.

\section{PHYSIOLOGICAL REDUNDANCY AND EXERCISE}

A hallmark of the responses to exercise is redundancy. This is an area of the investigators' expertise and briefly means that multiple overlapping mechanisms operating at many levels are responsible for generating many of the physiological responses to exercise. Notable examples of physiological redundancy include the many mechanisms that can evoke increases in blood flow to active muscles and the many mechanisms that contribute to the increase in ventilation with exercise (Forster et al. 2012; Joyner and Casey 2015). The teleological explanation for redundancy is that the ability to exercise is critical for survival of almost all species of animals. If one mechanism dominated (for example) the ability for muscle blood flow or ventilation to increase during exercise, the loss of such a mechanism would have devastating consequences for survival. Thus, for many physiological responses, no one single mechanism can be seen as "obligatory," at least to an organ system's "total" response to exercise, when the organism is intact.

Classic examples of redundancy in physiology come from the studies of David Donald in the 1960s showing that racing greyhounds maintained their ability to exercise even when their hearts were denervated, despite an attenuated heart-rate response to exercise (Donald et al. 1964). Donald later showed that the blood-pressure responses to exercise were also subject to redundant control (Joyner 2006). Similar observations have been made concerning the ventilatory responses to exercise (Forster et al. 2012). An important physiological tradeoff or balancing act is the interplay between the vast capacity of skeletal muscle to vasodilate during exercise and the ongoing need to regu- 
M.J. Joyner and J.A. Dempsey

late arterial blood pressure (Joyner and Casey 2015).

More recently, several so-called "master regulators" of the metabolic adaptations to exercise (including AMP-activated protein kinase [AMPK] and peroxisome proliferatoractivated receptor $\gamma$ coactivator $1 \alpha$ [PGC- $1 \alpha$ ) have been proposed, but when studies in knockout animal models are performed, remarkably normal adaptive responses can be seen (Jorgensen et al. 2005; Leick et al. 2008). That these master regulators are not obligatory again highlights the general principle of redundancy and extends it to the molecular level.

From an evolutionary perspective, animals that are adapted to high altitudes and capable of performing prodigious feats of exercise/endurance in hypoxia almost uniformly have leftshifted oxygen hemoglobin dissociation curves. Such a left shift facilitates the loading of oxygen to hemoglobin at high altitudes. Although there is phenotypic convergence toward a left shift and lower P50, the molecular basis of this shift at the DNA level is highly variable and unpredictable (Natarajan et al. 2016). These observations and those concerning PGC-1 $\alpha$ and AMPK show that physiological redundancy is a key feature of the adaptive responses to exercise from DNA to the whole organism.

\section{SYSTEMIC AND REMOTE RESPONSES TO EXERCISE}

We have already touched on the idea that feedforward and feedback neural signals and mechanisms are critical for exercise responses. We have also touched on the idea that a number of the major responses to acute exercise might be described as service functions designed to both meet the needs of the exercising muscle and preserve homeostasis.

Central command is a feedforward mechanism that is thought to cause the initial and very rapid increases in heart rate and ventilation that occur at the onset of exercise. There are also feedback mechanisms that maintain arterial blood pressure, drive ventilation, and help control body temperature during more prolonged bouts of exercise. In the case of the cardiovas- cular and respiratory responses to exercise, key feedback can come directly from the active skeletal muscles via fine afferents that sense the metabolic and mechanical state of the contracting muscles (Mitchell 2013). There are also baroand chemoreflexes located notably in the carotid sinus and body that respond to changes in blood pressure, arterial oxygen content, arterial $\mathrm{CO}_{2}$, and also $\mathrm{pH}$ (Joyner 2006; Forster et al. 2012). In the case of the baroreflexes, there is a resetting in the brainstem so that blood pressure can increase during exercise but remains regulated via changes in cardiac output and vascular resistance around an altered set point. Similar body temperature resetting also occurs likely in the hypothalamus (Gonzalez-Alonso et al. 2008). Complex interactive control theory and modeling has been used to explore how these regulatory systems operate.

Feedback control mechanisms also contribute to the regulation of blood glucose during prolonged exercise and increases in hormones like epinephrine, cortisol, and glucagon can be observed. Increases in these hormones can maintain blood glucose and delay the onset of hypoglycemia.

The mechanical effects of exercise can also have systemic effects. There can be improved endothelial function in vascular beds not directly involved in the exercise. For example, endothelial function can improve in the arms of individuals undergoing exercise training with their legs (Kingwell et al. 1997). This may be caused by an increase in shear stress via the mechanical effects of increased heart rate and blood pressure during leg exercise on the arms. Similarly, the mechanical forces operating on bone during contractions or as a result of impact can also stimulate bone remodeling as part of the so-called mechanostat hypothesis (Skerry 2006). Although there are obviously cellular signaling mechanisms that participate in these responses, the point that they can be remote from the exercising muscles per se is critical to an overall understanding of exercise.

Three other systemic or remote effects of exercise deserve mention. First, a number of signaling molecules including so-called myokines and exosomes are secreted by exercising 
Physiological Redundancy and Exercise

muscles (Pedersen and Febbraio 2012; Safdar et al. 2016). These have been identified in the past 10 to 15 years. However, cross-circulation studies performed in the 1960s clearly suggested that substances released from contracting muscles had remote effects like the insulin-independent promotion of increased glucose uptake (Goldstein 1961). The second remote effect of exercise is the mobilization of so-called progenitor cells in response to exercise (Witkowski et al. 2011). The extent to which these factors (myokines, exosomes, progenitor cells, etc.) participate in the systemic effects of exercise and contribute to various forms of structure remodeling discussed above is still being evaluated. An additional remote effect of training is the remodeling of autonomic centers in the brainstem that tend to inhibit sympathetic activity and promote increased vagal tone (Billman 2009; Mischel et al. 2015).

\section{EXERCISE, PHYSICAL ACTIVITY, AND RISK REDUCTION}

For many years, the primary beneficial mechanism(s) by which exercise reduced all causes of cardiovascular mortality and extended life was thought to be via reductions in traditional risk factors identified in epidemiological studies. In other words, exercise "worked" because it reduced blood lipid levels, blood pressure, blood glucose, and other traditional cardiovascular risk factors. However, more recent populationbased studies suggest that these and other risk factors explain only $\sim 50 \%$ of the protective effects of exercise on human health. Additionally, the protection conferred by exercise or physical activity is greater than that conferred by risk factor-modulating drugs. This is true even when the drugs cause much larger changes in the risk factor of interest (e.g., statins and cholesterol vs. exercise and cholesterol) (Joyner and Green 2009).

What are the sources of the extra risk reduction? A number of the mechanisms discussed earlier offer potential clues. First, structural remodeling of large arteries including coronary arteries would provide a margin of safety against coronary occlusion (Huonker et al.
2003). Such remodeling was clearly shown in the autopsy study of seven-time Boston Marathon champion Clarence DeMar who died of cancer in 1958 at the age of 70 (Currens and White 1961). Anatomical remodeling of coronary arteries has been confirmed in the Masai tribesman of Kenya and also in ultramarathon runners (Mann et al. 1972; Haskell et al. 1993). Second, a lower resting heart rate and improved vagal tone as a result of training or habitual high levels of physical activity is likely highly protective against potentially fatal ventricular arrhythmias. Third, myokines, adipokines, exosomes, and progenitor cells all may promote broadbased regenerative or disease-modifying effects in a number of tissues, including the cerebral circulation and brain. Fourth, improved endothelial function is antiatherogenic and antithrombogenic. Finally, there can be preconditioning effects in the heart that might improve survival in response to temporary ischemic effects (Powers et al. 2014). Some of the adaptations outlined above may be especially robust in response to more intense forms of exercise training that go beyond public health guidelines advocating $150 \mathrm{~min} /$ wk of moderate to vigorous physical activity (Lavie et al. 2015). In this context, a number of studies have shown that the carefully monitored application of high-intensity interval training similar to that used by athletes can benefit patients with a number of conditions (Weston et al. 2014).

\section{SUMMARY}

Because so much current exercise-related research is focused at the cellular and molecular level, in this review we sought to highlight our interest in the general principles of physiological redundancy. In this context, we have attempted to highlight how physiological redundancy modulates the marked effects of muscle contraction on whole-body homeostasis. We have also discussed how this helps explain the adaptations to training, and also the impressive health benefits that can accrue from regular physical activity. In each of these cases, the integrated responses to exercise are generally more than the simple sum of their component parts 
and usually cannot be predicted solely by the behavior of cellular or subcellular events. An additional essential insight stemming from redundancy is that there can be compensation for the loss-of-function in one or more components usually (and erroneously) deemed critical or obligatory to a normal physiological response. In the final analysis, we believe that renewed attention to physiological redundancy and related insights is critical to gain an overall understanding of exercise and to integrate findings made with reductionist experimental paradigms into a more coherent overall picture.

\section{ACKNOWLEDGMENTS}

The authors thank Drs. Jackie Limberg and Sarah Baker, Humphrey Petersen-Jones, B.S., for the critical comments on a draft of this review and Cheryl Baertlein for help in preparing the manuscript. We thank the many human subjects who have volunteered for studies in our laboratories over many years.

\section{REFERENCES}

Andersen P, Saltin B. 1985. Maximal perfusion of skeletal muscle in man. J Physiol 366: 233-249.

Asmussen E. 1981. Similarities and dissimilarities between static and dynamic exercise. Circ Res 48: I3-I10.

Bacon AP, Carter RE, Ogle EA, Joyner MJ. 2013. $\mathrm{VO}_{2 \max }$ trainability and high intensity interval training in humans: A meta-analysis. PLoS ONE 8: e73182.

Bayly WM, Hodgson DR, Schulz DA, Dempsey JA, Gollnick PD. 1989. Exercise-induced hypercapnia in the horse. J Appl Physiol (1985) 67: 1958-1966.

Billman GE. 2009. Cardiac autonomic neural remodeling and susceptibility to sudden cardiac death: Effect of endurance exercise training. Am J Physiol Heart Circ Physiol 297: H1171-H1193.

Chirico AM, Stunkard AJ. 1960. Physical activity and human obesity. N Engl J Med 263: 935-940.

Church TS, Thomas DM, Tudor-Locke C, Katzmarzyk PT, Earnest CP, Rodarte RQ, Martin CK, Blair SN, Bouchard C. 2011. Trends over 5 decades in U.S. occupation-related physical activity and their associations with obesity. PLoS ONE 6: e19657.

Currens JH, White PD. 1961. Half a century of running. Clinical, physiologic and autopsy findings in the case of Clarence DeMar ("Mr. Marathon"). N Engl J Med 265: 988-993.

Dempsey JA, Hanson PG, Henderson KS. 1984. Exerciseinduced arterial hypoxaemia in healthy human subjects at sea level. J Physiol 355: 161-175.
Donald DE, Milburn SE, Shepherd JT. 1964. Effect of cardiac denervation on the maximal capacity for exercise in the racing greyhound. J Appl Physiol 19: 849-852.

Ekblom B, Hermansen L. 1968. Cardiac output in athletes. $J$ Appl Physiol 25: 619-625.

Feldman DI, Al-Mallah MH, Keteyian SJ, Brawner CA, Feldman T, Blumenthal RS, Blaha MJ. 2015. No evidence of an upper threshold for mortality benefit at high levels of cardiorespiratory fitness. J Am Coll Cardiol 65: 629-630.

Forster HV, Haouzi P, Dempsey JA. 2012. Control of breathing during exercise. Compr Physiol 2: 743-777.

Goldstein MS. 1961. Humoral nature of the hypoglycemic factor of muscular work. Diabetes 10: 232-234.

Gonzalez-Alonso J, Crandall CG, Johnson JM. 2008. The cardiovascular challenge of exercising in the heat. J Physiol 586: 45-53.

Haskell WL, Sims C, Myll J, Bortz WM, St Goar FG, Alderman EL. 1993. Coronary artery size and dilating capacity in ultradistance runners. Circulation 87: 1076-1082.

Hawley JA, Hargreaves M, Joyner MJ, Zierath JR. 2014. Integrative biology of exercise. Cell 159: 738-749.

Hickson RC, Bomze HA, Holloszy JO. 1977. Linear increase in aerobic power induced by a strenuous program of endurance exercise. J Appl Physiol Respir Environ Exerc Physiol 42: 372-376.

Holloszy JO. 1967. Biochemical adaptations in muscle. Effects of exercise on mitochondrial oxygen uptake and respiratory enzyme activity in skeletal muscle. J Biol Chem 242: 2278-2282.

Holloszy JO, Narahara HT. 1965. Studies of tissue permeability. X: Changes in permeability to 3-methylglucose associated with contraction of isolated frog muscle. $J$ Biol Chem 240: 3493-3500.

Howden EJ, Perhonen M, Peshock RM, Zhang R, ArbabZadeh A, Adams-Huet B, Levine BD. 2015. Females have a blunted cardiovascular response to one year of intensive supervised endurance training. J Appl Physiol (1985) 119: $37-46$.

Huonker M, Schmid A, Schmidt-Trucksass A, Grathwohl D, Keul J. 2003. Size and blood flow of central and peripheral arteries in highly trained able-bodied and disabled athletes. J Appl Physiol (1985) 95: 685-691.

Jacobi A. 1919. Memoir of Sir Hermann Weber. Trans Am Climatol Clin Assoc 35: xx-xxiv.

Johnson BD, Saupe KW, Dempsey JA. 1992. Mechanical constraints on exercise hyperpnea in endurance athletes. J Appl Physiol (1985) 73: 874-886.

Johnson BD, Badr MS, Dempsey JA. 1994. Impact of the aging pulmonary system on the response to exercise. Clin Chest Med 15: 229-246.

Jorgensen SB, Wojtaszewski JF, Viollet B, Andreelli F, Birk JB, Hellsten Y, Schjerling P, Vaulont S, Neufer PD, Richter EA, et al. 2005. Effects of $\alpha$-AMPK knockout on exerciseinduced gene activation in mouse skeletal muscle. FASEB J 19: $1146-1148$.

Joyner MJ. 2006. Baroreceptor function during exercise: Resetting the record. Exp Physiol 91: 27-36.

Joyner MJ, Casey DP. 2015. Regulation of increased blood flow (hyperemia) to muscles during exercise: A hierarchy of competing physiological needs. Physiol Rev 95: 549601. 
Joyner MJ, Green DJ. 2009. Exercise protects the cardiovascular system: Effects beyond traditional risk factors. $J$ Physiol 587: 5551-5558.

Keul J, Dickhuth HH, Simon G, Lehmann M. 1981. Effect of static and dynamic exercise on heart volume, contractility, and left ventricular dimensions. Circ Res 48: I162I170.

Kingwell BA, Sherrard B, Jennings GL, Dart AM. 1997. Four weeks of cycle training increases basal production of nitric oxide from the forearm. Am J Physiol 272: H1070H1077.

Laughlin MH, Armstrong RB. 1982. Muscular blood flow distribution patterns as a function of running speed in rats. Am J Physiol 243: H296-H306.

Lavie CJ, Arena R, Swift DL, Johannsen NM, Sui X, Lee DC, Earnest CP, Church TS, O'Keefe JH, Milani RV, et al 2015. Exercise and the cardiovascular system: Clinical science and cardiovascular outcomes. Circ Res 117: 207-219.

Leick L, Wojtaszewski JF, Johansen ST, Kiilerich K, Comes G, Hellsten Y, Hidalgo J, Pilegaard H. 2008. PGC- $1 \alpha$ is not mandatory for exercise- and training-induced adaptive gene responses in mouse skeletal muscle. Am J Physiol Endocrinol Metab 294: E463-E474.

Lundby C, Montero D, Joyner M. 2016. Biology of $\mathrm{VO}_{2 \max }$ : Looking under the physiology lamp. Acta Physiol (Oxf) doi: 10.1111 /alpha.12827.

Mann GV, Spoerry A, Gray M, Jarashow D. 1972. Atherosclerosis in the Masai. Am J Epidemiol 95: 26-37.

McGuire DK, Levine BD, Williamson JW, Snell PG, Blomqvist CG, Saltin B, Mitchell JH. 2001. A 30-year follow-up of the Dallas Bedrest and Training Study. I: Effect of age on the cardiovascular response to exercise. Circulation 104: 1350-1357.

Mischel NA, Subramanian M, Dombrowski MD, LlewellynSmith IJ, Mueller PJ. 2015. (In)activity-related neuroplasticity in brainstem control of sympathetic outflow: Unraveling underlying molecular, cellular, and anatomical mechanisms. Am J Physiol Heart Circ Physiol 309: $\mathrm{H} 235-\mathrm{H} 243$.

Mitchell JH. 2013. Neural circulatory control during exercise: Early insights. Exp Physiol 98: 867-878.

Montero D, Lundby C. 2017. Refuting the myth of nonresponse to exercise training: "Non-responders" do respond to higher dose of training. J Physiol doi: 10.1113 JP273480.

Moore SC PA, Matthews CE, Berrington de Gonzalez A, Park Y, Katki HA, Linet MS, Weiderpass E, Visvanathan K, Helzlsouer KJ, Thun M, et al. 2012. Leisure time physical activity of moderate to vigorous intensity and mortality: A large pooled cohort analysis. PLoS Med 9: e1001335.

Morris JN, Heady JA, Raffle PA, Roberts CG, Parks JW. 1953. Coronary heart-disease and physical activity of work. Lancet 265: 1111-1120.

Morris RT, Laye MJ, Lees SJ, Rector RS, Thyfault JP, Booth FW. 2008. Exercise-induced attenuation of obesity, hyperinsulinemia, and skeletal muscle lipid peroxidation in the OLETF rat. J Appl Physiol (1985) 104: 708-715.
Musch TI, Friedman DB, Pitetti KH, Haidet GC, Stray-Gundersen J, Mitchell JH, Ordway GA. 1987. Regional distribution of blood flow of dogs during graded dynamic exercise. J Appl Physiol (1985) 63: 2269-2277.

Natarajan C, Hoffmann FG, Weber RE, Fago A, Witt CC, Storz JF. 2016. Predictable convergence in hemoglobin function has unpredictable molecular underpinnings. Science 354: 336-339.

Olsen RH, Krogh-Madsen R, Thomsen C, Booth FW, Pedersen BK. 2008. Metabolic responses to reduced daily steps in healthy nonexercising men. JAMA 299: 12611263.

Pedersen BK, Febbraio MA. 2012. Muscles, exercise and obesity: Skeletal muscle as a secretory organ. Nat Rev Endocrinol 8: 457-465.

Powers SK, Smuder AJ, Kavazis AN, Quindry JC. 2014. Mechanisms of exercise-induced cardioprotection. Physiology (Bethesda) 29: 27-38.

Rankinen T, Fuku N, Wolfarth B, Wang G, Sarzynski MA, Alexeev DG, Ahmetov II, Boulay MR, Cieszczyk P, Eynon $\mathrm{N}$, et al. 2016. No evidence of a common DNA variant profile specific to world class endurance athletes. PLoS ONE 11: $\mathrm{e} 0147330$.

Safdar A, Bourgeois JM, Ogborn DI, Little JP, Hettinga BP, Akhtar M, Thompson JE, Melov S, Mocellin NJ, Kujoth GC, et al. 2011. Endurance exercise rescues progeroid aging and induces systemic mitochondrial rejuvenation in mtDNA mutator mice. Proc Natl Acad Sci 108: 4135 4140.

Safdar A, Saleem A, Tarnopolsky MA. 2016. The potential of endurance exercise-derived exosomes to treat metabolic diseases. Nat Rev Endocrinol 12: 504-517.

Sarzynski MA, Ghosh S, Bouchard C. 2016. Genomic and transcriptomic predictors of response levels to endurance exercise training. J Physiol doi: 10.1113/JP272559.

Scheffler RW. 2015. The power of exercise and the exercise of power: The Harvard fatigue laboratory, distance running, and the disappearance of work, 1919-1947. J Hist Biol 48: $391-423$.

Skerry TM. 2006. One mechanostat or many? Modifications of the site-specific response of bone to mechanical loading by nature and nurture. J Musculoskelet Neuronal Interact 6: $122-127$.

Tipton CM. 1998. Contemporary exercise physiology: Fifty years after the closure of Harvard Fatigue Laboratory. Exerc Sport Sci Rev 26: 315-339.

Trappe S, Hayes E, Galpin A, Kaminsky L, Jemiolo B, Fink W, Trappe T, Jansson A, Gustafsson T, Tesch P. 2013. New records in aerobic power among octogenarian lifelong endurance athletes. J Appl Physiol (1985) 114: 3-10.

Weber H. 1918. On the influence of muscular exercise on longevity. Br Med J 1: 228-229.

Weston KS, Wisloff U, Coombes JS. 2014. High-intensity interval training in patients with lifestyle-induced cardiometabolic disease: A systematic review and meta-analysis. Br J Sports Med 48: 1227-1234.

Witkowski S, Jenkins NT, Hagberg JM. 2011. Enhancing treatment for cardiovascular disease: Exercise and circulating angiogenic cells. Exerc Sport Sci Rev 39: 93-101. 


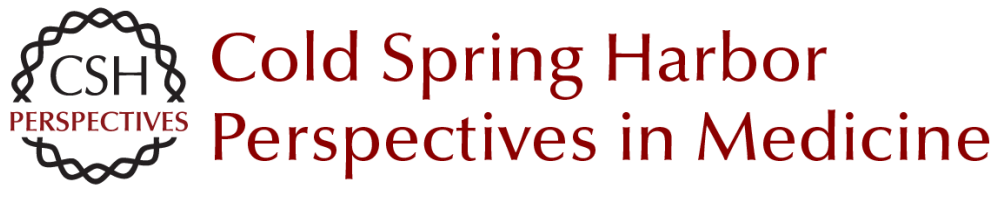

\title{
Physiological Redundancy and the Integrative Responses to Exercise
}

\author{
Michael J. Joyner and Jerome A. Dempsey \\ Cold Spring Harb Perspect Med 2018; doi: 10.1101/cshperspect.a029660 originally published online May \\ 10, 2017
}

\section{Subject Collection The Biology of Exercise}

Exosomes as Mediators of the Systemic

Adaptations to Endurance Exercise Adeel Safdar and Mark A. Tarnopolsky

Molecular Basis of Exercise-Induced Skeletal

Muscle Mitochondrial Biogenesis: Historical

Advances, Current Knowledge, and Future

Challenges

Christopher G. R. Perry and John A. Hawley

Exercise Metabolism: Fuels for the Fire Mark Hargreaves and Lawrence L. Spriet

Health Benefits of Exercise Gregory N. Ruegsegger and Frank W. Booth

Molecular Regulation of Exercise-Induced Muscle

Fiber Hypertrophy

Marcas M. Bamman, Brandon M. Roberts and

Gregory R. Adams

Physiological Redundancy and the Integrative

Responses to Exercise Michael J. Joyner and Jerome A. Dempsey

On the Run for Hippocampal Plasticity C'iana Cooper, Hyo Youl Moon and Henriette van Praag

Molecular Basis for Exercise-Induced Fatigue:

The Importance of Strictly Controlled Cellular $\mathrm{Ca}$

2+ Handling

Arthur J. Cheng, Nicolas Place and Håkan

Westerblad
Effects of Exercise and Aging on Skeletal Muscle Giovanna Distefano and Bret $H$. Goodpaster

Muscle-Adipose Tissue Cross Talk

Kristin I. Stanford and Laurie J. Goodyear

Performance Fatigability: Mechanisms and Task Specificity

Sandra K. Hunter

Adaptations to Endurance and Strength Training David C. Hughes, Stian Ellefsen and Keith Baar

The Bioenergetics of Exercise

$P$. Darrell Neufer

Effects of Exercise on Vascular Function,

Structure, and Health in Humans

Daniel J. Green and Kurt J. Smith

Control of Muscle Metabolism by the Mediator

Complex

Leonela Amoasii, Eric N. Olson and Rhonda

Bassel-Duby

Theoretical and Biological Evaluation of the Link between Low Exercise Capacity and Disease Risk Lauren Gerard Koch and Steven L. Britton

For additional articles in this collection, see http://perspectivesinmedicine.cshlp.org/cgi/collection/ 